\title{
Quality of Work-Life among Employees of University of The Gambia
}

\author{
Lamin W. Saidykhan \\ University of The Gambia \\ School of Business \& Public Administration \\ P.O. Box. 3035, MDI Road, Kanifing Municipality \\ Lamin B. Ceesay \\ University of The Gambia \\ School of Business \& Public Administration \\ P.O. Box. 3035, MDI Road, Kanifing Municipality
}

\begin{abstract}
Quality of work-life (QWL) is concerned with the welfare and satisfaction of employees on the job as well as off the job. The purpose of this research is to examine the QWL among the employees of the only national higher education university - University of The Gambia (UTG). Thus, our original contribution to research is that we examined an application of QWL in a context (i.e. UTG) that has not existed in extant literature. Summary of the results indicates that interestingly four aspects of QWL stand in employees' evaluation as "moderateto-high" motivators: (1) relations and co-operations, (2) autonomy of work, (3) organizational culture and (4) working climate. However, to "moderate-to-low" level of motivation with QWL aspects has been reported (1) job satisfaction and job security, (2) training and development, (3) work environment, (4) adequacy of resources, (5) compensation and rewards, and (6) facilities. These results are indeed critical to human resources development planning of the UTG. Also, results confirm the multidisciplinary and multisectoral nature of QWL and the managerial implications are thus unique to the case under study.
\end{abstract}

Keywords: Quality of work-life, University of the Gambia (UTG), Human resources development, Employee morale, workplace productivity.

\section{INTRODUCTION}

The performance and productivity of an organization depend on how effective and efficient it manages its resources (e.g. Kermansaravi, Navidian, Rigi\&Yaghoubinia, 2015; Darabi, Mehdizadeh, Arefi\&Ghasemi, 2013). Organizational resources vary and workforce or human resources constitute one of the most critical resources. The human resources scholars argue that an empowered and motivated workforce has significant implication on productivity (Monkevicius, 2014; Jebel, 2013). Human resource is an important asset to the organization and when they are dissatisfied, they become the organization's first enemy (Swamy, Nanjundeswaraswamy and Rashmi, 2015). Further, the noticed that to sustain in the competitive market, organizations must treat the employees as assets, not liabilities through responsible humanized job design process known as quality of work-life (QWL). philosophically, QWL is a set of principles that recognizes the importance of human resources (i.e. the people) resource in any organization. Thus, can be trusted to make responsible and valuable contributions to 
the organization, hence they should be treated with dignity and respect at all time (Lokanadha\& Mohan, 2010, p. 827).

When employees feel that their organization care about them, they tend to express more citizenship behaviour toward the organization (Alfonso, Zenasni, Hodzic\& Ripoll, 2016). Besides, if employees are not satisfied with their QWL, they try to look for better opportunities elsewhere. Thus, QWL is an important determinant of employees' welfare and future career prospects (Balachandar, Panchanatham\& Subramanian, 2013). Happy employees are served as goodwill ambassadors for organizations by reinforcing its good image through positive messages (Monkevicius, 2014; Fapohunda, 2013). Scholars recognize that QWL is related to on-the-job performance and organizational productivity (e.g. Fapohunda 2013; Vasita\&Prajapat, 2014), organizational commitment (Permarupan, Al- Mamun \& Saufi, 2013;), productivity (Janmohammadi, Shahmandi, Khooravesh\&Ghanizadeh, 2015), life satisfaction and service quality (Mohamad \& Mohamed, 2012).

However, despite the plethora of research interest on this theme, we have seen quite an underexplored study of QWL in the context of academic and research institutions, particularly at the University of The Gambia. Universities are critical human development institutions, and thus provides an ideal context for the study of QWL (Mirkamali\& Thani, 2011). As a conduit for workforce development and growth, Universities could leverage QWL strategies to strengthen workforce performance and quality of work-life balance (Taher, 2013; Singh \& Singh, 2015).

Therefore, the purpose of this study seeks to investigate the quality of work-life (QWL) of the employees of The University of The Gambia (UTG). UTG is the first and the only Public University in The Gambia. It has been established 18 years ago (in 1999) and since then, it has graduated thousands of people from diverse fields of study. However, the university's development and growth has been very slow due to several reasons. One of such reasons is workforce planning and development. The problems related to recruitments, staff development, and staff retention remain key deterrents to the growth of the institution. Understanding the perception of the quality of work-life in the context of the UTG would foster its human resource development strategy and programs.

Using an empirical, quantitative survey approach, this study measures staff perceptions of QWL at the UTG. The study is organized first, a literature review on quality of worklife; second, is the methodological approach adopted; part three illustrates the analysis of the findings and the final part demonstrates the policy recommendations and limitations of the study.

\subsection{The Concept of Quality of Work-Life}

\section{THEORETICAL REVIEW}

The origin of QWL can be traced back to the industrial revolution (e.g. Bindu \& Yashika, 2014), a period when employees were considered as machines. During such periods, key wages were the main determinants of employees' motivation (Ganguly, 2010, p. 209). While that remains unsustainable, poor morale and occasional sabotage etc. became prevalent in organizations (Bindu \& Yashika, 2014, p. 14). To mitigate these negative vibes, researchers conduct experiments such as the "Hawthorne Studies" to understand people's behaviour at work and the ways to improve their job satisfaction without sacrificing the overall objectives of organizations. Finding suggests that productivity and employee satisfaction can be simultaneously achieved (Ganguly, 2010). 
The continuous research consequently gave birth to the concept of QWL in the 1960s when the then General Motors employee, Irving Bluestone, used the expression "Quality of work-life" for the first time (see Goode, 1989, cited by Martel \& Dupuis, 2006). However, the use of the term QWL became much more prevalent after the international conference on QWL held in Arden House, New York in 1972 that led to the formation of International Centre for QWL in 1973 to promote research and the exchange of information concerning mental health at work (Martel \& Dupuis, 2006; Gani\& Ahmad, 1995).

Since the introduction of QWL and despite the substantial body of research on the concept in recent years, there has not been any universally or generally accepted definition of the term. Different views exist as to what is QWL. It has become an umbrella term for a multitude of activities and different people has defined it differently at different times (Ganguly, 2010). Moreover, QWL may be addressed and analyzed according to several disciplines (Newton \& Leckie, 1977). For instance, it may be considered as 1) a "goal" by focusing on work improvement through creating more involving and satisfying jobs and work environment for employees 2) a "process" by seeking the active involvement of all employees at all levels of the organization; and 3) a "philosophy" where organization recognize the fundamental human dignity of all its members and thus recognizing employees as assets to be realized and developed rather than as a cost to be controlled (Carlson, 1981). Therefore, a precise definition of the boundaries and subject matter of QWL remains a debate. Nevertheless, a review of some of the definitions given by researchers is present in table 1 - providing more comprehensive definitions of the QWL.

Table 1: Selected perspectives of Quality of Work Life

\begin{tabular}{|c|c|}
\hline AUTHORS & DEFINITION \\
\hline $\begin{array}{l}\text { Pettman, } \\
\text { Newtonand } \\
\text { Leckie, (1980) }\end{array}$ & $\begin{array}{l}\text { QWL is a subsystem of socio-economic systems and as such defined it as the } \\
\text { study of the structure and processes of the dynamic field of work relations } \\
\text { within a complex and interdependent environment of many systems. }\end{array}$ \\
\hline Sinha (1982) & $\begin{array}{l}\text { QWL refers to the relationship between a worker and his environment, adding } \\
\text { the human dimension to the technical and economic dimensions within which } \\
\text { work is normally viewed and designed. }\end{array}$ \\
\hline $\begin{array}{l}\text { Shamir and } \\
\text { Salomon (1985) }\end{array}$ & $\begin{array}{l}\text { QWL covers the individual's job-related well-being and the extent to which his } \\
\text { or her work experience is rewarding, fulfilling, and devoid of stress and other } \\
\text { negative personal consequences. }\end{array}$ \\
\hline Corcoran (1986) & $\begin{array}{l}\text { QWL is referred to as a variety of techniques for raising productivity and job } \\
\text { satisfaction by altering the nature of the workplace, increasing the employee's } \\
\text { stake in the organization, and/or creating new opportunities for employee } \\
\text { participation in decision making. }\end{array}$ \\
\hline $\begin{array}{l}\text { Martel and } \\
\text { Dupuis (2006) }\end{array}$ & $\begin{array}{l}\text { Defined QWL based on the general Quality of Life Model corresponds to a } \\
\text { condition experienced by the individual in his or her dynamic pursuit of his or } \\
\text { her hierarchically organized goals within work domains where the reduction of } \\
\text { the gap separating the individual from these goals is reflected by a positive } \\
\text { impact on the individual's general quality of life, organizational performance } \\
\text { and consequently the overall functioning of the society. }\end{array}$ \\
\hline Armstrong (2006) & $\begin{array}{l}\text { QWL is the sense of satisfaction people obtains from their work by, so far as } \\
\text { possible, reducing monotony, increasing variety, autonomy and responsibility, } \\
\text { and avoiding placing people under too much stress. }\end{array}$ \\
\hline Kaur (2016) & $\begin{array}{l}\text { QWL in the education sector is defined as the bond between the teachers and } \\
\text { working environment of the universities. }\end{array}$ \\
\hline
\end{tabular}


Following the review of selected perspectives, the focus of QWL is placed on employees' relationship with the organization, employees' job satisfaction, the work environment, the economic, social and psychological aspects of work, and employees' overall satisfaction with life (i.e. their quality of life). Therefore, it can be concluded that QWL is multidimensional and imprecise, and thus challenging to operationalize.

\subsection{Dimensions of Quality of Work Life}

The disagreement among researchers about QWL does not only stop at the definition of the term but it extends to its dimensions as well. To unions it may mean fair wages and good working conditions (Wurf 1982); to a worker, it may be about the assembly line, a safe working conditions, and a fair treatment with dignity and respect from managers and supervisors, an opportunity for advancement and career growth. Likewise, the academics, QWL may be tied to all the above (Joshi, 2007).

Thus, it is understood that many factors contribute to QWL, ranging from ranging from the subjective to objective dimensions, and financial to non-financial dimensions (Dahl, Nesheim \&amp; Olsen 2009) and extrinsic to intrinsic dimensions (Lewis, Brazil, Krueger, Lohfeld \&amp; Tjam,2001). For instance, Newton, Leckie and Pettman, (1979), they adopted five broad components dimension of QWL. These includes access to work; net attractiveness of the employment package; perceptions, attitudes and responses; actors and their inter-relationship; and measurement. Sinha (1982) studied QWL and quality of life according to six QWL dimensions, namely: job satisfaction; job involvement; intrinsic motivation; controls and influence; work values; and job attractiveness. Moreover, Levine (1983) also proposed six dimensions of QWL in his paper "Self-developed QWL measures" which include the degree to which superiors treat subordinates with respect and have confidence in their abilities; extent to which life outside of work affects life at work; challenging work; equitable promotions; variety in the daily work routine; and self-esteem. Saklani (2003) adopts thirteen dimensions of QWL: adequate and fair compensation; reward and penalty administration; job security; human relations and social aspect of life; work load and job stress; equity, justice and grievance handling; opportunity to use and develop human capacity; balance in life; opportunity for career growth; physical working environment; participation in decisionmaking; fringe benefits and welfare measures; and image of organization in the society. Finally, Corcoran (1986) study on "improving the quality of work life in public schools" suggested the seven dimensions: challenging job; autonomy to make decisions about ones work; sense of belonging to a group or community; decent physical working conditions; safety and security at work place; rewards associated with work - both intrinsic and extrinsic rewards; treating employees with dignity and respect. He however concluded that even though successful organizations have used most, or all the dimensions listed above to effectively implement QWL programs, there is no universal remedy for QWL. What works in one setting may fail in another due to poor implementation.

The review of literature shows that the debate on the concept and dimensions of QWL is far from over. Given the subjectivity of the concept, it seems the disagreement among scholars and researchers might be dragged into the future and they might never come to a common ground on the concept and determinants of QWL. The universality of the concept remains a myth. Thus, adopting Swamy, et al. (2015), this study utilized nine QWL dimensions: work environment, organization culture and climate; relation and cooperation; training and development; compensation and rewards; facilities; Job satisfaction and job security; autonomy of work; and adequacy of resources. 


\subsection{Empirical review of Quality of Work Life in the Education Sector}

QWL in the education sector is defined as the bond between the teachers and the working environment of the universities (Kaur, 2016). Several scholars have examined QWL in the education sector. Many of these studies focused on the relationships between QWL and variables such as job involvement (Mehdipour, Boushehri, Saemi \& Rayegan, 2012), job satisfaction (Bhavani \& Jegadeeshwaran, 2014; Kaur, 2016; Ganguly, 2010; Vasita, \&Prajapat, 2014), motivation (Baleghizadeh and Gordani, 2012; Jofreh, Yasini, Dehsorkhi \& Hayat, 2013; Kaur, 2016), organization commitment (Daud et al., 2015; Farid, Izadi, Ismail, \& Alipour, 2015; Afsar, 2014), occupational stress (Hans, Mubeen, Mishra \& Al-Badi, 2015), etc. However, several other studies focused on investigating employees' satisfaction with the general level of QWL as well as the relationship of QWL with demographic variables such as age, gender, work experience, income, employment status (full time or part-time) which are the objectives of the present study.

Nanjundeswaraswamy and Swamy (2013) conducted a study on the QWL of employees in private technical institutions, and results reveal a significant relationship between QWL of teaching and non-teaching staffs. On the contrary, the results of the study conducted by Mehrotra and Khandelwal (2015) to investigate the association of demographic factors (gender and salary) on QWL of teaching employees in private technical institutions in Bareilly Region, India. Results revealed a significant association between QWL and demographic characteristics (gender and salary) of the employees. Further, Elamparuthy and Jambulıngam (2016) observe college teachers' perception of QWL among college teachers, and the study indicates that the level of QWL of college teachers is low and report no significant effect of gender difference. Manju (2014) also investigated teachers' perception of QWL among 100 secondary school teachers from Mysore City. The result found that the majority of them (70.2\%) possessed an average level of QWL. Moreover, these results confirm a significant gender difference among teachers in their evaluation of QWL. Iran by Mehdipour et al., (2012) investigate the on the relationship between the QWL and job involvement of Iranian physical education teachers. The results revealed that QWL differs significantly based on demographic factors such as gender, work experience, and academic degree.

It could be observed that from the empirical review that the findings of previous studies indicate mix results in terms of the overall level of employees' QWL in educational institutions. Despite a growing research stream on the QWL, limited studies exist in the African education institutions, particularly in the Gambia. Thus, this study seeks to investigate the following propositions:

H1: There is a significant gender difference in the evaluation of QWL.

H2: There is a significant difference between academic and non-academic staff in the evaluation of QWL.

H3: There is a significant difference between staff earning and their evaluation of QWL.

H4: There is a significant difference between the level of education and the evaluation of QWL

H5: There is a significant difference between the staff on different categories of work experience and their evaluation of QWL.

H6: There is a significant difference in different age category and their evaluation of QWL. 


\subsection{Research approach}

\section{RESEARCH METHODOLOGY}

The purpose of this research is to evaluate QWL among UTG staff in the Gambia. A survey design was adopted. Following several scholars, this study uses an online questionnaire (Leary, 2001, Ceesay, 2017). The questionnaire comprises of questions about measurement variables as the dependent variable of QWL and the independent variables about demographic factors (Bhattacherjee, 2012). Also, a correlational type of investigation is conducted to test the study's hypothesis (i.e. to determine whether QWL and demographic variables of the research subjects are related).

\subsection{Sampling population}

The target population for this study is the staff of the University of the Gambia (UTG). A total of 480 staff participated in this study. Out of which 148 are administrative staff (147 full time and 1 part-time) and 332 academic staff (248 full time and 84 part-time). Auxiliary staff (including security guards, drivers, cleaners, gardeners, labourers, groundsmen) with a total of 78 staff which are categorized under administrative staff either have very low or zero formal English education and since a structured selfadministered online questionnaire is used for collecting data, these people could not participate in the study because of their inability to read, understand or respond meaningfully to the questions due to their inadequate understanding of English. Thus, a probability sample was not possible because not all elements of the population have equal chances of being included in the sample. The researcher had to resort to judgement sampling which is used when a limited category of people who are best positioned to provide the information that is required for the research are selected in the sample (Sekaran, 2003).

The size of the sample depends on the research question(s) and objectives (Saunders et al., 2009). However, "survey research is generally notorious for its low response rates" (Bhattacherjee, 2012, p.80) especially when it is conducted through online questionnaires - usually, a response rate of $30 \%$ or lower is typical and reasonable (Saunders et al., 2009). Given these reasons and to boost response rate, the remaining 402 staff (i.e. the 480 total staff population less the 78-auxiliary staff) were used as the sample. 145 staff responded to the questionnaire which is a response rate of $36 \%$.

\subsection{The instrument for data collection}

The instrument used for collecting the primary data was a set of structured selfadministered questionnaire which is adopted from the study of Swamy et al. (2015). The questionnaire is developed in English and is divided into two sections: section one and section two. Section one contains questions relating to personal and demographic variables. Questions regarding age, gender, work experience, employment status, monthly salary, level of education etc. were asked in this section and the data was analyzed using descriptive statistics. Section two consisted of 50 item QWL scale to measure nine dimensions of QWL which include: work environment, organizational culture and climate, relation and co-operation, training and development, compensation and rewards, facilities, job satisfaction and job security, the autonomy of work, and adequacy of resources. The questions in this section were closed-ended questions designed with 5 points Likert type scale ranging from strongly disagree " 1 " to strongly agree " 5 ". "To reduce response bias, questions $3,11,16$ and 45 were negatively worded. The responses are reverse scored on these survey items to determine the status of QWL" (Swamy et al., 2015, p. 286). Each dimension has multiple questions as shown in Table 3. 


\begin{tabular}{lll}
\hline$\#$ & Measurement Scales adopted & $\begin{array}{l}\text { Number } \\
\text { statements }\end{array}$ \\
\hline $\mathbf{1}$ & Work Environment & 6 \\
\hline $\mathbf{2}$ & Organizational Culture and Climate & 7 \\
\hline $\mathbf{3}$ & Relations and Co-operations & 6 \\
\hline $\mathbf{4}$ & Training and Development & 4 \\
\hline $\mathbf{5}$ & Compensation and Rewards & 5 \\
\hline $\mathbf{6}$ & Facilities & 5 \\
\hline $\mathbf{7}$ & Job Satisfaction and Job Security & 8 \\
\hline $\mathbf{8}$ & Autonomy & 6 \\
\hline $\mathbf{9}$ & Adequacy of Resources & 3 \\
\hline
\end{tabular}

Table 2: Dimensions of QWL and Question Numbers in the questionnaire

It is worth mentioning that the majority of QWL studies used the questionnaire developed by Walton (Jebel, 2013; Mehdipour et al, 2012; Jofreh et al, 2013; Parvar et al, 2013). However, the researcher decided to use a different questionnaire (i.e. the one developed by Swamy et al, 2015) for this research due to two main reasons. Firstly, researchers believe that the scale developed by Swamy et al. (2015) is more comprehensive than the one developed by Walton because they initially considered 27 important QWL components based on their frequency of usage in literature which also includes Walton's scale. They then conducted explanatory factor analysis (principal component analysis) to reduce the components and based on this analysis they finally selected nine QWL dimensions which are used in this study. Secondly, Timossi, Pedroso, Francisco, and Pilatti (2008) highlighted two main shortcomings of Walton's questionnaire: (1) they argued that Walton's QWL model presented difficulties to some respondents in terms of interpreting and understanding the original form of the model, due to the use of "more elaborate terms and expressions". According to them, this issue came to light during the development of some studies related to QWL, and after a lot of applications of the model, (2) they also contended that the lack of direct and specific questions or the definition of each criterion was another difficulty with Walton's model. They concluded that based on these perspectives, the need for an instrument of easy comprehension by respondents with direct and specific questions is justified.

Also, the Cronbach's alpha coefficient above 0.70 is adequate reliability (Leary, 2001). The alpha coefficient previously obtained for the instrument by Swamy et al., (2015) was 0.88 and for the present research, is 0.907 which both show a high level of reliability.

\subsection{Demographic Characteristics of Respondents}

\section{FINDINGS AND DISCUSSIONS}

The demographic profiles of the respondents including gender, education, monthly salary, employment status, designation, age, and work experience. In total 145 individuals responded to the questionnaire. The result indicates that majority of the respondents (77\%) are male while $23 \%$ are female. A greater per cent of the respondents (51\%) have a master's degree, followed by $40 \%$ with bachelor's degree or below. Only a smaller per cent (9\%) of the respondents hold PhD. According to the employment category, the majority of the respondents (75.4\%) are academic staff and the rest (24.6\%) being administrative staff. 
Distribution according to income shows that a less than half (40.7\%) of UTG staff are earning a monthly salary of GMD 10,000 or less, most of them (53.1\%) earn a staggering amount between GMD 10,001 and GMD 20,000. Only small per cent (6.2\%) of respondents are earning above GMD 20,000. With a bigger per cent (93.8\%) of respondents earning GMD 20,000 GMD or less, we could infer from this results that a significant majority of UTG staff are earning GMD 20,000 or less which is less than 450 USD $^{1}$. Additionally, a bigger per cent $(97.2 \%)$ of respondents are reported as full-time staff while only a smaller per cent (2.8\%) reported as part-time, tenure staff of the UTG.

Among the respondents, $43.6 \%$ are aged 30 years or below, $30.1 \%$ are between 31 to 40 years, and $26.3 \%$ are aged more than 40 years. Finally, a whopping $59.5 \%$ of the respondents have a work experience of 5 years or less, $19.8 \%$ with 6 to 10 years, and $20.7 \%$ with more than 10 years of work experience. With close to $60 \%$ of respondents having 5 years or fewer work experiences coupled with their age and level of salary (over 93\% earning less than 500 USD).

\subsection{UTG Staff's Level of Satisfaction with their Overall QWL and its Dimensions}

Descriptive statistic was conducted to determine the level of satisfaction of UTG staff with regards to their overall QWL and its dimensions. Based on a five-point Likert scale used to measure QWL, the minimum and maximum rating of QWL and each of the nine dimensions were computed as well as the mean and standard deviation to determine the satisfaction with the overall level of QWL and its dimensions. The result reveals that the respondents are moderately dissatisfied with their overall evaluation of QWL with a mean of(2.96) and a standard deviation of(0.47). Similar results were found by Baleghizadeh and Gordani (2012); Mirkamali and Thani (2011); and Jofreh et al., (2013). It, however, contradicts the findings of Hans et al, (2015) who have conducted a study on occupational stress and quality of work-life in private colleges of Oman (Muscat) and found that respondents were moderately satisfied with their QWL. It is also not in line with the findings of Rehan and Arora (2014) who also found that Punjubi University Teachers were moderately satisfied with their QWL. The geographic setting and the respondent under which the study is carried out could affect the study result. Therefore, we need to be courteous when we compare the results because as pointed out by Bustillo, Macías, Antón, Esteve, and Contreras (2009, p. 16) "when we try to apply the characteristics of work and employment that affect the wellbeing of the worker internationally, great difficulties arise because there are structural and cultural differences, as well as different levels of economic development, that make those "characteristics" likely to differ from country to country".

The respondents reported the highest level of satisfaction in their evaluation of relations and co-operations with a mean (M) score of (3.56) and a standard deviation of (0.58) and lowest values in facilities with a mean score of (2.49) and a standard deviation of (0.82). It also shows that the respondents are moderately satisfied with only three dimensions of QWL: relations and co-operations $(M=3.56$ and $S D=$ 0.58), autonomy of $\operatorname{work}(M=3.33$ and $S D=0.60)$ and organizational culture and climate $(M=3.17$ and $S D=0.62)$. The following contentions can be deduced from these results: (1) the respondents have a harmonious and cordial relationship with their colleagues and superiors and thus leading to a strong sense of community at UTG; (2) they perceived that they have freedom, independence and discretion in determining the pace and procedures of their work. This means employees express flexibility in their job. This might be a fact that part of the work could be completed at work. For instance, academic staff can grade examination and assessment scripts at home. Also, working hours are flexible; (3) they also perceived the norms and values (i.e. culture) existing in UTG to be satisfactory. They feel they are involved in decision making by providing 
comments and suggestions, do not experience gender discrimination and are proud to be working for UTG.

The respondents are moderately dissatisfied with the remaining six dimensions of QWL: job satisfaction and job security $(M=2.96$ and $S D=0.60)$, training and development $(M=$ 2.86 and $S D=0.77)$, work environment $(M=2.82$ and $S D=0.65)$, adequacy of resources ( $M$ $=2.57$ and $S D=0.89)$, compensation and rewards $(M=2.49$ and $S D=0.81)$, and facilities $(M=2.49$ and $S D=0.82)$. Therefore, we could infer the following impressions to these perceptions: (1) the respondents do not feel satisfied with or secured about their job. The dissatisfaction with their job may be due to a combination of factors such as working conditions, pay and benefits etc. However, their job insecurity is evident in the fact that even full-time UTG staff are appointed on a contract basis. This means the end of the contract could lead to the termination of one's employment. This could lead to a high level of turnover and a low level of commitment and it may be the reason why UTG is not attracting highly experienced individuals as a majority of the respondents (up to $60 \%$ ) have a work experience of 5 years or less; (2) they are not satisfied with the level of training and development they are getting from UTG to perform their job well. In other words, they feel that the training programs provided by UTG are not enough to gain the required skills and qualifications to achieve their objectives. This is not surprising as the greatest number (up to 91\%) of respondents including academic staff do not have a PhD; (3) the working conditions of UTG are not favourable to the respondents. This could be explained by the fact that at UTG, most of the offices and classrooms are not properly ventilated in the sense that only a few offices are equipped with air conditioning (AC) even though some are equipped with ceiling fans.

However, some of these ACs and fans are not functioning and thus making it unbearable for lecturers to stay in their offices sometimes due to high temperature -given that The Gambia is a very hot country. In addition to this, the conditions of the toilet facilities are often inhumane hence making it very unconducive to use them. Worse than these is the fact that some staff especially academic staff don't even have office space. These conditions together with other issues might be responsible for their dissatisfaction with their (respondents) working conditions; (4) the respondents feel that the resources provided to facilitate the performance of their duties are not enough. This is very much expected because at UTG even the most basic resources such as white A4 size papers, white-board markers, projectors, cartridge for photocopying and printing machines etc. are not enough.

Furthermore, most of the staff especially the academic staff are not provided with computers to facilitate their work. Also, no limited internet facility across its campuses make it even worst. Thus, since the primary channel of communication at UTG is through email, some staff do not get information at the right time and hence leading to ineffective information dissemination (ineffective communication channels) (Ceesay and Sanyang, 2018). Besides, without computers and the internet, research becomes very difficult. Moreover, libraries are ill-equipped and classroom spaces, classroom furniture remain inadequate. Thus, adequacy of resource was expected to occupy the last position when it comes to satisfaction of QWL of UTG staff.; (5) respondents feel that they are not adequately and fairly compensated for the work that they do. Moreover, they feel UTG does not pay salary by considering responsibilities at work neither are their rewards linked to performance. This might be explained by the fact that the greatest number of the respondents (up to 93.8\%) including those with $\mathrm{PhD}$ are 
paid less than USD 450 (less than USD 5,400 per annum) which could be one of the lowest salaries paid to university staff in the world. For instance, in Uganda, University lecturers are paid an average gross annual salary of USD 8,998; in Kenya, USD 16,959; in Tanzania, USD 11,750; in Zimbabwe, USD 17,378; in Botswana, USD 31,279; in Namibia, USD 28,542 and in Swaziland, USD 22,532. This does not include the remunerations of senior lecturers, associate professors and professors as they are paid higher (pay increases as qualification increases) (Mushemeza, 2016, p. 243); (6) finally, they are not satisfied with welfare facilities such as transportation, social security benefits, health insurance, food etc. Despite the university's contribution to towards employee's social security, other welfare services such as food and health insurance are not provided to employees. Also, transportation is only provided in one of the campuses and for the remaining campuses, employees must struggle on their own to get to work which is quite hectic during rush hours.

\subsection{Relationship Between QWL and Demographic Factors}

To answer the third research question - is there any relationship between UTG staff's QWL and their demographic variables of 6 different hypotheses were drawn:

Hypotheses One: There is a significant difference between men and women concerning their QWL. To test these hypotheses an independent t-test is conducted, and the results of the t-test revealed that on average, female $(M=3.0544, S D=0.46709)$ have bigger mean than their male counterparts $(M=2.9553, S D=0.47088)$ in their evaluation of.However, this difference, 0.09905, at 95\% confidence interval $(-0.08822,0.28631)$, is not statistically significant, $t$-value(137) $=1.046, p=0.297$. Thus, we can say that there is no significant difference between men and women concerning their QWL. Hence hypotheses one is not substantiated. The present study replicates the findings of $\mathrm{Al}$ Zboon et al. (n.d.) whose results also indicate no significant mean difference in QWL between male and female Jordanian special education teachers. The results are also consistent with the findings of Manju (2014) but it contradicts with the findings of Mehdipour et al, (2012).

Hypotheses two: The results of the t-test reveal that on average, non-academic staff $(M=$ 3.1011, $S D=0.48754)$ are more satisfied with their QWL than academic staff $(M=2.9174$, $S D=0.44293)$. Furthermore, this difference, -0.18378 , at $95 \%$ confidence interval ($0.35880,0.00891)$, is statistically significant, t-value $(140)=-2.078, p=0.040$. Thus, we can say that there is a significant difference between academic staff and non-academic staff in their evaluation of QWL. Hence hypotheses two is substantiated. Nanjundeswarawamy and Swamy (2013) also found a significant difference between teaching and non-nonteaching staff and in their case too, non-teaching staff were more satisfied with their QWL than teaching staff in technical institutions. However, Elamparuthy and Jambulingam (2016) found no significant difference between the designation of the respondents and their observed levels of overall quality of work life. However, his comparison was between lecturer, senior lecturer, assistant professor and professor and not between academic and non-academic staff as is the case for the present study.

Hypotheses Three: There is a significant difference between the staff on different levels of monthly salary concerning their QWL. To test this hypothesis, a one-way ANOVA is conducted. Levene's test is not significant. Therefore, we have not violated the assumption of homogeneity of variance. The results of the ANOVA test found a statistically significant difference between staff with different levels of monthly salary in their evaluation of $Q W L(F=3.208 ; p=0.043)$. Therefore, hypotheses three is 
substantiated. Staff earning GMD 10,000 or less are more satisfied $(M=3.0824 ; S D=$ 0.48082), followed by those earning more than $G M D 20,000(M=2.8978 ; S D=0.46438)$ and then those earning between GMD 10,001 to GMD 20,000 ( $M=2.8816$; $S D=$ 0.45330).These results mirror the results of Almalki et al. (2012) who also found a significant mean monthly pay difference among primary health care nurses in the Jazan region, Saudi Arabia with regards to their QWL.

Since ANOVA test could only tell us that a significant difference exists among the different groups but could not determine which groups the true differences lie, a posthoc test was administered using Hochberg's GT2 procedure to find out which monthly salary group of respondents differs significantly from other groups. It is observed from the Post Hoc analysis that when the respondents earning GMD 10,000 or less are compared to those earning between GMD 10,001 to GMD 20,000, a significant mean difference in their evaluation of is revealed (sig. is less than 0.05). Respondents earning GMD 10,000 or less are more satisfied in their evaluation of than those earning GMD 10,001 to GMD 20,000. However, when respondents earning GMD 10,000 or less are compared to those earning more than GMD 20,000 and those earning between GMD 10,001 to GMD 20,000 are compared to those earning more than GMD 20,000, no significant mean differences in their evaluation of QWL is revealed in both cases (sig. is greater than 0.05). Therefore, we could conclude that the true difference lies between respondents earning GMD 10,000 or less and those earning between GMD 10,001 to GMD 20,000 .

Hypotheses Four: There is a significant difference between the staff with different level of education concerning their QWL. To test this hypothesis, a one-way ANOVA is conducted. Levene's test is not significant. Therefore, we have not violated the assumption of homogeneity of variance. The results of the ANOVA test find that a statistically significant difference exists between staff with different levels of education and their evaluation of $Q W L(F=3.851 ; p=0.024)$. Therefore, hypotheses four is substantiated. Staff with bachelor's degrees or less are more satisfied $(M=3.0931 ; S D=$ $0.49009)$, followed by those with master's degree $(M=2.8884 ; S D=0.43552)$ and then those with $P h D(M=2.8215 ; S D=0.49575)$. Thus, we can infer that as the respondents' level of education increase, their QWL falls (i.e. an inverse linear relationship exists between the respondents' evaluation of QWL and their level of education). Bhavani and Jegadeeshwaran (2014) also found a significant mean difference between women teachers in higher education have different levels of educational qualification in their opinion on QWL. On the contrary, Ogungbamila\&Idemudia (2016) did not find any significant relationship between educational qualifications and QWL of police personnel working in selected states in south-west Nigeria.

Again, a posthoc test was administered using Hochberg's GT2 procedure to find out which educational group of respondents differs significantly from other groups. It is observed from the Post Hoc analysis that when the respondents with bachelor's degree or below were compared to those with master's degree, a significant mean difference in their QWL is revealed (sig. is less than 0.05). This confirms our earlier findings. However, when respondents with bachelor's degree or below were compared to those with PhD and those with master's compared to those with $P h D$, no significant difference in their QWL is revealed in either case (sig. is greater than 0.05). Therefore, we could conclude that the true difference lies between respondents with bachelor's degree or below and those with a master's degree. 
Hypotheses Five: There is a significant difference between the staff on different categories of work experience concerning their QWL. To test this hypothesis, a one-way ANOVA is conducted. The results of the ANOVA test indicate that there is no statistically significant difference among staff on different categories of work experience concerning their $Q W L$ ( $F=0.932 ; p=0.396)$. Therefore, hypotheses five is not substantiated. These results are following the results of Manju (2014).

Hypotheses Six: There is a significant difference between the staff on different age categories concerning their evaluation of QWL. The results of the ANOVA test indicate that there is no statistically significant difference between staff on different age categories concerning their $Q W L(F=0.636 ; p=0.531)$. Therefore, hypotheses five is not substantiated. These results contradict with the findings of Mehdipour et al (2012).

\subsection{Conclusion}

\section{CONCLUSION, RECOMMENDATIONS AND LIMITATIONS}

The present study is set out to investigate how satisfied UTG staff are with regards to their QWL and its dimensions. It investigates whether there are significant differences in the evaluation of the quality of Work-Life at the University of The Gambia (UTG). This study leverages a cross-sectional survey method of data collection was used to collect primary data with the help of a set of structured self-administered questionnaire which is adopted from the study of Swamy et al. (2015). Data were analyzed with SPSS 24 and several tests have been conducted ranging from descriptive statistics to determine the overall QWL, independent T-test to compare the mean differences for some demographic factors and one-way ANOVA for others. Several key findings have been revealed by the study.

Our study finds several interesting results. Firstly, the descriptive statistics revealed that UTG employees who participated in the research are moderately dissatisfied with their overall QWL on a five-point Likert scale. Furthermore, it also indicates that the respondents are moderately satisfied with only three out of the nine dimensions of QWL investigated in this study: relations and co-operations, the autonomy of work, and organizational culture and climate. Moreover, the respondents reported the highest level of satisfaction in the category of relations and co-operation, followed by the autonomy of work, organizational culture and climate, job satisfaction and job security, training and development, work environment, adequacy of resources, compensation and rewards, and the lowest in facilities. Thirdly, results indicate a significant mean difference in QWL between academic staff and non-academic staff. From the results, it is concluded that non-academic staff who participated in this research are more satisfied with their QWL than their academic counterparts. Finally, the ANOVA results revealed that evaluation of QWL differs significantly among staff with different educational qualification and monthly salary. Post-Hoc tests were conducted to determine between which groups the true difference lie and the results shows that in terms of monthly salary the difference lies between those earning GMD 10,000 or less and those earning between GMD 10,001 to GMD 20,000 with those earning GMD 10,000 or less being more satisfied with their QWL. In terms of educational qualifications, the test indicates that the true difference lies between holders of bachelor's degree or less and master's degree holders with those with bachelor's or below being more satisfied.

This result is logical given that at UTG, staff with bachelor's degree or less are usually the ones earning less than GMD 10,000, and given that most of them are fresh graduates and newly entering into the labour force with little experience, their options in the job market might be limited. Staff expressed content for the employment opportunity than 
their counterparties with higher qualifications and better opportunities in the job market. This is also consistent with the fact that even though the results of the study did not indicate any significant difference in the respondents' QWL in terms their experience, but the means of the different experience groups show that as the respondents' experience increase, their QWL fall. However, despite the mix results in related literature, our findings remain consistent with several studies, too.

\subsection{Managerial implication}

The findings of this study have several implications for UTG decision-makers and management. Improving the UTG staff's QWL will improve the psychological wellbeing of the staff and will make them more committed and satisfied with their jobs. Improving QWL stimulates employee's performance and productivity. Therefore, UTG's management should endeavour to improve their staff's QWL to benefit from these positive effects of QWL. The following recommendations are proposed: (1) UTG management should scrap the policy of employing staff on a three-year contract basis. They can instead put new employees on a 6-month probationary period to assess their competence.

After this period, if the employee's performance is satisfactorily barring some minimum performance requirements, s/he should be employed on a full-time basis which will lead to improved job security for the staff and reduce labour turnover (2) UTG management should also endeavour to collaborate with universities in Europe, America, Asia and other African countries to have their employees (especially academic staff) trained by those universities to higher educational levels such as PhD. Short-term training facilities for staff is essential QWL.

Also, collaboration with journal publishers would stimulate work particularly learning and research. (3) To improve the working conditions, offices and classrooms should be properly ventilated. Additional classrooms and office spaces should be constructed to curb classroom shortage and to provide office space to those staff without one. Sanitation facilities should be addressed as a matter of urgency. (4) The management of UTG should ensure that basic teaching and learning materials are provided for. Internet facilities makes a big difference in QWL. (5) To strengthen the co-operation among the general staff body as well as between the staff and the management through team building and socialization programs. (6) Finally, restructure UTG pay and remuneration in line with the universities in the sub-region. This would greatly limit staff turnover rate while attracting more qualify staff.

\subsection{Limitations}

The limited scales on QWL hinders the research on QWL. Through researchers' discretions, several dimensions of QWL have been used. This could impact the true result of the study. Also, the sampling method adopted in this study is a judgmental sampling. This limits the generalizability of the result. Finally, the number of respondents could be improved. Other universities in The Gambia have not been included in this research. Since UTG is the only public University in The Gambia, future research could observe these weaknesses for improved research quality.

\section{Declaration}

The authors declare no conflict of interest. 


\section{REFERENCES}

1. Afsar, S. T. (2014). Impact of the quality of work-life on organizational commitment: A comparative study on academicians working for state and foundation universities in Turkey. International Journal of Social Sciences,III(4), 124-152.

2. Kaye A. R., \& Sutton, M. J. D. (1985). "Productıvity and qualıty of workınglife for officeprincipals and the implications for officeautomation". Office Technology andPeople, 2(4) 267-286. Permanent link to this document:http://dx.doi.org/10.1108/eb022637.Downloadedon: 15 July 2015, At: 23:48 (PT)

3. Alfonso, L., Zenasni, Hodzic, S., \& Ripoll, P. (2016). Understanding the mediating role of quality of work life on the relationship between emotional intelligence and organizational citizenship behaviors. Psychological Reports, 118(1) 107-127.

4. Almalki, M. J., FitzGerald, G., \& Clark, M. (2012). The relationship between quality of work life and turnover intention of primary health care nurses in Saudi Arabia.

BMCHealthServicesResearch,12(314).Retrievedfrom:http://www.biomedcentral.com/1472$6963 / 12 / 314$

5. Al-Zboon, E. K., Al_Dababneh, K. A. H., \& Ahmad, J. (n.d.). Quality of work life:perceptions of Jodanian special education teachers. Education: 135(3): 380-388.

6. Armstrong, M. (2006). A handbook of human resource management practice (10th ed.).London and Philadelphia: Kogan Page Limited.

7. Balachandar, G., Panchanatham, N., \& Subramanian, K. (2013). Quality of work life, the power of insurance company: Impact of personal factors on the quality of work life of the officers. Management and Marketing, XI(1) 123-133.

8. Balaram, B., Soumendra, D., \& Murthy, V. (2015). Quality of work life -A literature review.International Journal in Management and Social Science, 3(3), 2321-1784. Retrieved from: http://ssrn.com/abstract=2592416

9. Baleghizadeh, S., \&Gordani, Y. (2012). Motivation and quality of work life among secondary school EFL teachers. Australian Journal of Teacher Education: 37(7), Article 3. Retrieved from: http://ro.ecu.edu.au/ajte/vol37/iss7/3.

10. Benjamin, O. A. (2015). Impact of organisational culture and leadership style on quality of worklife among employees in Nigera. African Journal for the Psychological Studyof Social Issues: 18(1): 109-121.

11. Bhattacherjee, A. (2012). Social Science Research: Principles, Methods, and Practices(2nd ed.). Textbooks Collection. Book 3. http://scholarcommons.usf.edu/oa_textbooks/3

12. Bhavani, M., \&Jegadeeshwaran, M. (2014). Job satisfaction and quality of work life - A case study of women teachers in higher education. SDMIMD Journal ofManagement. 5(2).

13. Bindu, J., \&Yashika, S. (2014). Quality of work life with special reference to academic sector. Research Journal of Management Sciences, 3(1), 14-17.

14. Bolhari, A., Rezaeean, A., Bolhari, J., Bairamzadeh, S., \&Soltan, A. A. (2011). The relationship between quality of work life and demographic characteristics of information technology staffs. 2011 International Conference on ComputerCommunication and Management, Proc .of CSIT vol.5. IACSIT Press, Singapore

15. Bustillo, R. M., Macías, E. F., Antón, J. I., Esteve, F. \& Contreras R. R. (2009). Indıcatorsof job quality in the European Union. DirectorateGeneral For Internal PolıciesPolıcy Department A: Economic And ScientıficPolıcy Employment And SocialAffairs, European Parliament.

16. Carlson, H. C. (1981).Quality of work life model. Education + Training 23(4) 99 - 100. Permanent link to this document: http://dx.doi.org/10.1108/eb002061Downloaded on: 07 February 2016, at: 02:43 (PT)

17. Ceesay LB, Sanyang L (2018) The Impact of Digital Media Advertising on Consumer Behavioral Intention towards Fashion and Luxury Brands: Case of the Gambia. Arabian J Bus Manag Review 8: 369 . 
18. Ceesay LB (2017) Consumer-Band Association: Determinants of Consumer Bank Switching Intention, Case of the Gambia Retail Banking Sector. J Bus Fin Aff 6: 295. doi: 10.4172/21670234.1000295

19. Corcoran, T. B. (1986). Improving the quality of work life in the public schools. Researchfor Better Schools, Inc., Philadelphia, Pa. Retrieved from:http://files.eric.ed.gov/fulltext/ED374561.pdf

20. Cronbach, L. J. (1951). Coefficient alpha and the internal structure of tests. Psychometrika, 16(3). 297-334.

21. Dahl, S. A., Nesheim, T., \& Olsen, K. M. (2009). Quality of work-concept andmeasurement. Working Papers on the Reconciliation of Work and Welfare inEurope (REC-WP 05/2009). RECWOWE Publication, Dissemination and Dialogue. Centre,Edinburgh. Retrieved from:http://www.socialpolicy.ed.ac.uk/recwowepudiac/working_papers/

22. Darabi, M., Mehdizadeh, A. H., Arefi, M., \&Ghasemi, A. A. (2013). Relationship between quality of work life and job satisfaction on school teachers in Kermanshah. Journalof Educational Management Studies, 3(4) 508-513.

23. Dargahi, H., \&Yazdi M. K. S. (2007). Quality of work life in Tehran University of Medical Sciences Hospitals' clinical laboratories employees. PakJ Med Sci: 23(4): 630-633.

24. Daud, N., Yaakob, Y., \& Ghazali, S. N. M. (2015). Quality of work life and organizational commitment: empirical investigation among academic in public institution of higher learning. $I J$ $A B E R, 13(7), 6127-6144$. Retrieved from:http://www.serialsjournals.com/serialjournalmanager/pdf/1457773303.pdf.Accessed on: 28 April, 2017.

25. Elamparuthy, D., \&Jambulingam, S. (2016). A study on quality of work life of college teachers' perception. International Journal of Research in Management 1(6).

26. Fapohunda, T. M. (2013). An evaluation of the perceptions and experiences of quality of work life in Nigeria. International Journal of Academic Research in Management(IJARM), 2(4) 96-108.

27. Farid, H., Izadi, Z., Ismail, I. A., \&Alipour, F. (2015). Relationship between quality of work life and organizational commitment among lecturers in a Malaysian public research university. The Social Science Journal: 52: 54-61

28. Field, A. (2013). Discovering stailstics using IBM SPSS statistics (4th ed.). Los Angeles, London, New Delhi, Singapore, Washington DC. SAGE.

29. Fields, M. W., \& Thacker, J. W. (1992). Influence of quality of work life on company and union commitment. The Academy of Management Journal, 35(2), 439-450Published by: Academy of Management. Stable URL:http://www.jstor.org/stable/256382Accessed:08-12-2016 13:38 UTC

30. Gallie, D. (2003). The quality of working life: Is Scandinavia different? EuropeanSociological Review, 19(1), 61-79. Published by: Oxford University Press. StableURL: http://www.jstor.org/stable/3559475. Accessed: 08-12-2016 13:50 UTC.

31. Ganguly, R. (2010). Quality of worklife and job satisfaction of a group of university employees. Asian Journal of Management Research, 209-216.

32. Gani, A., \& Ahmad, R. (1995). Correlates of quality of work life: an analytical study.Indian Journal of Industrial Relations, 31(1), 1-17. Published by: Shri Ram Centrefor Industrial Relations and Human Resources. Stable URL:http://www.jstor.org/stable/27767392Accessed:10-11-2016 14:45 UTC

33. Garg, C. P., Munjal, N., Bansal P., \& Singhal A. K. (2012). Quality of work life: An overview. International Journal of Physical and Social Sciences, 2(3), 231-242.

34. Gilgeous, V. (1998). Manufacturing managers: their quality of working life. IntegratedManufacturing Systems, 9(3), 173-181. Permanent link to this document:http://dx.doi.org/10.1108/09576069810210466. Downloaded on: 01 May 2015, At:22:26 (PT). 
35. Gupta, B., \& Hyde, A. M. (2013). Demographical Study on Quality of Work Life in Nationalized Banks. Vision, 17(3), 223-231.

36. Gupta, P., \& Gupta, R. (2013). Comparative study between permanent and contractual teachers' quality of work life: A study in higher education. International Journal ofAdvanced Research in Management and Social Sciences 2(8), 231-244.

37. Hamidi, F., \&Mohamadi, B. (2012). Teachers' quality of work life in secondary schools.International Journal of Vocational and Technical Education, 4(1), 1-5.

38. Hans, A., Mubeen, S. A., Mishra, N., \& Al-Badi, A. H. H. (2015). A study on occupational stress and quality of work life (QWL) in private colleges of Oman (Muscat). GlobalBusiness and Management Research: An International Journal, 7(3), 55-68.

39. Harish,.K., \&Subashini, K. (2014). Quality of work life in Indian industries - A case study. International Journal of Innovative Research in Science, Engineering and Technology, 3(10), 1679916804.

40. Hitt, M. A., Amos, Jr., O. M., \& Warner, L. (1983). Social factors and company location decisions: technology, quality of life and quality of work life concerns. Journal ofBusiness Ethics, 2(2), 89-98 Published by: Springer. Stable URL:http://www.jstor.org/stable/25071380Accessed:08-12-2016 13:34 UTC

41. Hsu, M. Y., \&Kernohan, G. (2006). Dimensions of hospital nurses' quality of work life.Journal of Advanced Nursing, 54(1), 120-130.

42. Huzzard T. (2003). The convergence of the quality of working life and competitiveness: $A$ currentSwedish literature review. Stockholm, Sweden, National Institute for Working Life.

43. Ilyas, S. A. M. (2013). Quality of work-life model for teachers of private universities in Pakistan. Quality Assurance in Education, 21(3), 282 - 298. Permanent link to this document: http://dx.doi.org/10.1108/QAE-Feb-2012-0006. Downloadedon: 10November 2016, At: 06:25 (PT)

44. Indumathy, R., \&Kamalraj, S. (2012). A study on quality of work life among workers with special reference to textile industry in Tirupur District - A Textile Hub.International Journal of Multidisciplinary Research 2(4), 265-281.

45. Jain, Y., and Thomas R. (2016). A study on quality of work life among the employees of a leading pharmaceuticals limited company of Vadodara district. InternationalJournal of Applied Research, 2(5), 926-934.

46. James, G. (1992). Quality of Working Life and Total Quality Management. InternationalJournal of Manpower, 13(1), 41-58. Permanent link to this document:http://dx.doi.org/10.1108/EUM0000000000902. Downloaded on: 01 May 2015, At:22:24 (PT).

47. Janmohammadi, B., Shahmandi, E., Khooravesh, M., \&Ghanizadeh, P. A. (2015). Study of the dimensions of quality of work life and organızationalproductivity of the staff oftax organization of Alborz Province. Indian Journal of Fundamental and AppliedLife Sciences, 5(1) 297-308.

48. Jebel, G. (2013). Quality of work life and organizational commitment of employees incommercial bank of Ethiopia (Unpublished Master's Thesis). Addis AbabaUniversity, Addis Ababa.

49. Jofreh, M., Yasini, A., Dehsorkhi, H. F., and Hayat, A. (2013). The relationship between EFL teachers' quality of work life and job motivation. Middle-East Journal ofScientific Research 13 (3), 338-346.Joshi, R. J. (2007). Quality of work life of women workers: role of trade unions. IndianJournal of Industrial Relations, 42(3), 355-382. Published by: Shri Ram Centre forIndustrial Relations and Human Resources. Stable URL:http://www.jstor.org/stable/27768080Accessed:10-11-2016 14:40 UTC

50. Kaur, K. (2016). Impact of quality of work life on overall job satisfaction level and motivational level: a study of government universities in Punjab. Pacific BusinessReview International, 8(8).

51. Kaye, A. R., \& Sutton, M. J. D. (1985). Productivity and quality of working life for office principals and the implications for office automation. Office Technology andPeople, 2(4) 267-286. Permanent link to this document:http://dx.doi.org/10.1108/eb022637. Downloaded on: 15 July 2015, At: 23:48 (PT). 
52. Kermansaravi, F., Navidian, A., Rigi1, S. N., \&Yaghoubinia, F. (2015). The relationship between quality of work life and job satisfaction of faculty members in Zahedan University of Medical Sciences. Global Journal of Health Science, 7(2).

53. Leary, M. R. (2001). Introduction to Behavioral Research Methods (3rd ed.). Boston, London, Toronto, Tokyo, Sydney \& Singapore: Allyn \& Bacon

54. Letooane, M. K. (2013). Factors impacting on the quality of work life: a case study ofUniversity " $A$ ", (Unpublished Master's dissertation). Durban University ofTechnology, Durban, South Africa.

55. Levine, M. F. (1983). Self-developed quality of work life measures. Journal ofOccupational Behavior, 4(1), 35-46. Published by: Wiley. Stable URL:http://www.jstor.org/stable/3000225Accessed:08-12-2016 13:53 UTC

56. Lewis, D., Brazil, K., Krueger, P., Lohfeld, L., \&Tjam, E. (2001). Extrinsic and intrinsic determinants of quality of work life. Leadership in Health Services, 14(2), 9 - 15. Permanent link to this document: http://dx.doi.org/10.1108/13660750110391539

57. Lokanadha, R. M. \& Mohan, R. P. (2010). Quality of work life of employees: emerging dimensions. Asian Journal of Management Research.

58. Lokanadha, R. M., \& Mohan, R. P. (2010). Quality of work life of employees: emerging dimensions. Asian Journal of Management Research, 827-839.

59. Luthans, F. (2011). Organizational behavior: an evidence-based approach (12th ed.). New York. McGraw-Hill/Irwin.

60. Manju, N. D. (2014). Quality of work life: perception of school teachers. InternationalJournal of Education and Psychological Research (IJEPR), 3(2), 77-80.

61. Martel, J. P., \& Dupuis, G. (2006). Quality of work life: theoretical and methodological problems, and presentation of a newmodel and measuring instrument. SocialIndicators Research, 77(2), 333-368. Published by: Springer. Stable URL:http://www.jstor.org/stable/27522585Accessed:10-11-2016 14:48 UTC.

62. McShane, S. L., \& Von Glinow, M. A. (2010). Organizational behavior : emergingknowledge and practice for the real world (5th ed.). New York, McGraw-Hill/Irwin.

63. Mehdipour, A., Boushehri, S. N. S., Saemi, E., \&Rayegan, A. (2012). Relationship between the quality of working life and job involvement of Iranian physical education teachers. Studies in Physical Culture and Tourism, 19(4), 185-190.

64. Mehrotra, R., \& Khandelwal, V. (2015). Association of demographic variables (gender and salary) on quality of work life of teaching employees in private technical institutions in Bareilly Region. International Journal of Education and Science ResearchReview, 2(2).

65. Mirkamalia, S. M., \& Thani, F. N. (2011). A Study on the Quality of Work Life (QWL) among faculty members of University of Tehran(UT) and Sharif university of Technology (SUT). Procedia - Social and Behavioral Sciences 29, 179 - 187. Available online at: www.sciencedirect.com

66. Mirvis, P. H., \& Lawler III, E. E. (1984). Accounting for the quality of work life. Journalof Occupational Behaviour, 5(3), 197-212. Published by: Wiley. Stable URL:http://www.jstor.org/stable/3000131Accessed:10-11-2016 14:32 UTC

67. Mohamad, M., \& Mohamed W. N. (2012). A model of quality of work life, life satisfaction and service quality. Asian Journal of Business Research, 2(2).

68. Momeni, B., Shafipour, V., Esmaeili3, R., \&Charati, J. Y. (2016). The relationship between the quality of work life and sleep in nurses at the intensive care units of teaching hospitals in Mazandaran, Iran. Journal of Nursing and Midwifery Sciences: 3(1): 28-34.

69. Monkevicius, A. (2014). Quality of workinglife concept and empirical indicators.Intellectual Economics, 8(1-19) 8-24.

70. Mushemeza, E. D. (2016). Opportunities and challenges of academic staff in higher education in Africa. International Journal of Higher Education, 5(3), 236-246. D0I:10.5430/ijhe.v5n3p236. 
71. Nanjundeswaraswamy, T. S., \& Sandhya, M. N. (2016). Quality of work life components:A literature review. The International Journal of Indian Psychology, 4(1), 12-36.

72. Nanjundeswaraswamy, T. S., \& Swamy, Q. R. (2013). Qualıty of work life of employees inprivatetechnicalınstitutions. International Journal for Quality Research, 7(3) 3-14.

73. Newton, K. (1978). Some socio-economic perspectives on the quality of working life. International Journal of Social Economics, 5(3), 179-187. Permanent link to thisdocument: http://dx.doi.org/10.1108/eb013829.

74. Newton, K., \& Leckie, N. (1977). What's quaality of work life?definition, notes, andbibliography. Discussion Paper No. 100, Minister of Supply and Services Canada.Catalogue No. EC25-100/1977 ISBN $0-662-01346-8$

75. Newton, K., Leckie, N., \& Pettman, B. O. (1979). The quality of working life. InternationalJournal of Social Economics, 6(4), 197-234. Permanent link to this document:http://dx.doi.org/10.1108/eb013836

76. Nirenberg, J. (1986). The quality of work life issue: the corporation as the next political frontier. International Journal of Manpower, 7(3), 27 - 36. Permanent link to this document: http://dx.doi.org/10.1108/eb045069Downloaded on: 24 February 2016, at: 08:24 (PT)

77. Ogungbamila, A., \&Idemudia, E. S. (2016). Gender differences in quality of work life of police personnel in two selected states in south-west, Nigeria. Gender \& Behavior, 14(1), 7019-7027

78. Parvar, M. R. F., Allameh, S. M., and Ansari, R. (2013). Effect of quality of work life on organizational commitment bySEM (case study: OICO company). InternationalJournal of Academic Research in Business and Social Sciences: 3(10): 135-144.DOI: 10.6007/IJARBSS/v3i10/285. URL: http://dx.doi.org/10.6007/IJARBSS/v3-i10/285.

79. Permarupan, P. Y., Al- Mamun A., \&Saufi R. A. (2013). Quality of work life on employees' job involvement and affective commitment between the public and private sector in Malaysia. Asian Social Science, 9(7). Retrieved from: http://dx.doi.org/10.5539/ass.v9n7p268

80. Pettman, B. O., Newton, K., \& Leckie, N. (1980). a systematic framework for quality of working life studies. International Journal of Manpower, 1(2), 20 - 24. Permanent link to this document: http://dx.doi.org/10.1108/eb044824.

81. Rahman, M., Ali, R., \& Islam, F. (2014). A Study on quality of work life among workers with special reference to state owned commercial banks in the northern region of bangladesh. Global Journal of Management and Business Research: AAdministration and Management 14(9) Version 1.0.

82. Rajshekhar, J. (2011). Quality of work life and family life balandf of the employees workingin BPO sector (Dotoral dissertation).Maharaja SayajıraoUnıversıty Of Baroda,Vadodara, India. Published by ProQuest LLC.

83. Rehan R., \& Arora R. S. (2014). Overall quality of work life and gap analysis: a study of punjabi university teachers. International Journal of Advance Research inComputer Science and Management Studies, 2(9), 351-357.

84. Saklani, D. R. (2003). Quality of work life: instrument design. Indian Journal of IndustrialRelations, 38(4), 480-503. Published by: Shri Ram Centre for Industrial Relationsand Human Resources. Stable URL: http://www.jstor.org/stable/27767867Accessed: 10-11-2016 14:33 UTC

85. Saraji, G. N., and Dargahi, N. (2006). Study of quality of work life (QWL). Iranian J PublHealth, 35(4), pp.8-14.

86. Saunders, M., Lewis, P., and Thornhill, A. (2009). Research methods for business studentsfifth edition (5th ed.). Edinburgh Gate, Harlow, Pearson Education Limited.

87. Sekaran, U. (2003). Research methods for business: A skill-building approach (4th ed.).United States of America: John Wiley \& Sons, Inc.

88. Shamir, B., and Salomon, I. (1985). Work-at-home and the quality of working life. TheAcademy of Management Review, 10(3), 455-464. Published by: Academy ofManagement. Stable URL: http://www.jstor.org/stable/258127Accessed: 08-12-2016 13:55 UTC.

89. Singh, O. P., \& Singh, S. K. (2015). Quality of work life of teachers working in higher educational institutions: a strategic approach towards teacher's excellence. International Journal of Advance Research in Computer Science and Management Studies, 3(9), 180-186. 
90. Sinha, P. (1982). Quality of working life and quality of life. Indian Journal of IndustrialRelations, 17(3), 373-394. Published by: Shri Ram Centre for Industrial Relationsand Human Resources. Stable URL: http://www.jstor.org/stable/27768677 Accessed: 08-12-2016 13:52 UTC

91. Sirgy, M. J., Efraty, D., Siegel, P., and Lee, D. J. (2001). A new measure of quality of work life (qwl) based on need satisfaction and spillovertheories. Social IndicatorsResearch, 55(3), 241-302. Published by: Springer. Stable URL:http://www.jstor.org/stable/27526956Accessed:10-11-2016 14:41 UTC.

92. Swamy, D. R., Nanjundeswaraswamy, T. S., \& Rashmi, S. (2015). Quality of work life: Scale development and validation. International Journal of Caring Sciences, 8(2) 281-300.

93. Tabassuma, A., Rahmanb, T., \& Jahan, K. (2011). Quality of work life among male and female employees of private commercial banks in Bangladesh. InternationalJournal of Economics and Management 5(1), 266-282.

94. Taher, A. (2013). Variations of quality of work life of academic professionals in Bangladesh. European Journal of Training and Development, 37(6), 580 - 595. Permanent link to this document: http://dx.doi.org/10.1108/EJTD-05-2013-0060. Downloaded on: 10 November 2016, At: 06:30 (PT)

95. Terry, P. (1974). The quality of working life. Industrial and Commercial Training, 6(7), 301-303. Permanent link to this document: http://dx.doi.org/10.1108/eb003402. Downloaded on: 07 August 2015, At: 01:46 (PT).

96. Timossi, L. S., Pedroso, B., Francisco, A. C., and Pilatti, L. A. (2008, October). Evaluationof quality of work life: An adaptation from the walton's QWL model. XIVInternational conference on industrialengineerıng and operations management: The integrationof productive

97. chain with an approach to sustainable manufacturing. Rio de Janeiro, Brazil.

98. Vasita, M.L., \&Prajapat, K. (2014). A study of qualıtyof work life and its impact on job satısfactıonın selected highereducatıonınstıtutıons of western rajasthan. Annamalainternatıonal Journal of BusinessStudies\& Research (AIJBSR), 6(1)26-34.

99. Vijay, S. A., Sekar, P. C., \& Vidhya, C. S. H. (2014). Quality of work life among the call center workers inIndia: A cross sectional study. Sona Global Management Review 9(1).

100. Wurf, J. (1982). Labor's view of quality of working life programs. Journal of BusinessEthics, 1(2), 131-137. Published by: Springer. Stable URL:http://www.jstor.org/stable/25071321 Accessed:08-12-2016 13:50 UTC

101. Xhakolları, L. (2011). Constructs of quality of work life: A perspective of mental health professionals. SocıalStudies, 2(5), 123-130. 